\title{
Basic Regularities of the Haline Stratification Long-Term Evolution in the Black Sea
}

\author{
A. I. Mizyuk, M. V. Senderov*, G. K. Korotaev \\ Marine Hydrophysical Institute of RAS, Sevastopol, Russian Federation \\ *maxim.senderov@mhi-ras.ru
}

\begin{abstract}
Purpose. At present the process of formation of haline stratification in the Black Sea is poorly studied. The current state of the basin is considered to be close to equilibrium. However, having been analyzed, the long-term observations testify to a tendency towards desalination of the sea surface layer and salination of the deep waters. The goal of the study is to obtain a complete pattern of the haline stratification formation in the basin and the characteristic time scales of its long-term climatic evolution.

Methods and Results. Numerical calculations of the Black Sea circulation which is formed being influenced by water exchange through the Bosporus, river runoff, precipitation and evaporation, are compared with the laboratory simulation results obtained previously using the NEMO model. It is shown that the time period of formation of the upper and lower Bosporus currents is of a characteristic time scale 20 years. Relatively short period of adaptation of the Bosporus water exchange to the external conditions testifies that on the climatic scale, the strait should be in a quasiequilibrium state. The results of the numerical experiments also show that, against the background of the initially preset constant salinity of the Black Sea, the vertical haline stratification is formed rather rapidly due to the fact that the upper forty-meter layer is desalinated by the river runoffs. This leads to formation of a halocline in the 10-40 m layer. In the deeper layers, salinity increases slowly owing to the Marmora Sea water inflow. Each of the calculations shows that intense desalination of the surface layer lasts $70-80$ years, whereupon its salinity grows slowly.

Conclusions. As a result, the characteristic adaptation period of the basin stratification to the changes in the external factors constitutes 70-100 years. After the equilibrium regime is settled, slow quasistationary evolution of the basin fields takes place. Analysis of the obtained results enabled us to deduce the equations for describing slow evolution of the haline stratification.
\end{abstract}

Keywords: haline stratification, halocline, Black Sea, numerical modeling, Bosporus Strait.

Acknowledgments: the work was performed in the Marine Hydrophysical Institute of RAS, with financial support of the Russian Science Foundation (grant No. 17-77-30001).

For citation: Mizyuk, A.I., Senderov, M.V. and Korotaev, G.K., 2019. Basic Regularities of the Haline Stratification Long-Term Evolution in the Black Sea. Physical Oceanography, [e-journal] 26(6), pp. 569-583. doi:10.22449/1573-160X-2019-6-569-583

DOI: $10.22449 / 1573-160 \mathrm{X}-2019-6-569-583$

(C) 2019, A. I. Mizyuk, M. V. Senderov, G. K. Korotaev

(C) 2019, Physical Oceanography

\section{Introduction}

The Black Sea is a semi-enclosed basin connected with the Sea of Marmora by the Bosporus Strait. A number of large rivers flow into the Black Sea; due to this fact its waters are significantly desalinated, whereas the values of the Marmora Sea salinity are higher. As a result, a two-layer structure of currents is maintained in the strait. In the surface layers, more desalinated waters, being influenced by the seas' level difference, propagate from the Black Sea to the Marmora Sea. Denser salt waters are transferred in the opposite direction and concentrated in the bottom layer of the strait. The salt inflow to the Black Sea is associated with the lower Bosporus current that brings saline waters of the Marmora Sea to the basin. At present, the salinity balance of the Black Sea is on average close to 
equilibrium. This means that the salt inflow provided by the lower Bosporus current is on average completely or almost completely compensated by its removal through the surface layer of the strait. Since salinity of the Marmora Sea waters is approximately two times higher than that of the Black Sea surface waters, the water volume transported by the upper Bosporus current should two times exceed the one transported by the lower Bosporus current.

River runoff, evaporation prevailing over precipitation and salt inflow through the Bosporus Strait form vertical haline stratification of the Black Sea waters. Vertical salinity distribution is characterized by its relatively weak change up to the depths 70-90 m. Below, at the depths 90-300 m, there is rather a sharp halocline (the layer of a high vertical salinity gradient), and then right up to the basin bottom salinity again changes insignificantly. The salinity difference between the upper and lower layers of the sea is about $4.5 \%$. Since almost everywhere in the Black Sea salinity contribution to formation of the sea water density is higher than that of temperature, the structures of the main pycnocline and halocline are almost the same.

Currently the process of formation of the haline stratification in the Black Sea is poorly studied. The present state of the basin is traditionally considered to be close to equilibrium. However, having been analyzed, the long-term observations $[1,2]$ show a tendency to desalination of the sea surface layer and salination of its deep waters. Rather a short series of observations does not permit to draw the distinctions between the trend and the phase of long-period oscillations. A more detailed research of evolution of the Black Sea haline stratification on the climatic scale should help to advance credible hypotheses on the subject.

The paleographic studies show that the Black Sea has underwent a few cycles of isolation and reunification with the World Ocean. The Black Sea was a freshwater lake for the last time was about 7500 years ago. Then due to the tectonic processes, the oceanic salt waters began to inflow to the Black Sea basin through the Bosporus Strait. According to the hypothesis in [3], the earthquake has provoked sudden opening of the Bosporus. By that time, the Black Sea level was significantly lower than the ocean one, and a waterfall had formed near the Bosporus Strait mouth that contributed to rapid rise of the sea level and increase of its water salinity.

The less radical hypothesis suggests that water exchange with the ocean was restored gradually and change in the haline regime of the Black Sea basin was of evolutional character. One way or another, when the basin averaged salinity became noticeable, formation of the vertical haline stratification should begin. One of the first papers aimed at studying the process of formation of the vertical haline stratification was, apparently, [4] where climatic changes of the Black Sea were investigated on the scales of several thousand years. In the present work, the Black Sea haline stratification was numerically modeled at various stages of its evolution from a freshwater lake to its current state. The calculation domain included real geometry of the Black and Azov seas, the Bosporus Strait and the eastern part of the Marmora Sea. The water circulation and its vertical stratification were formed only due to the river runoff and the inflow of highly saline Marmora Sea waters to the Black Sea basin. In a few performed numerical experiments, constant salinity in the Black Sea was prescribed as the initial conditions. These simulations showed 
that for all the initial conditions, water exchange between the Black Sea and the Marmora Sea was settled first of all. Then vertical stratification with a pronounced halocline is formed, later on it evolves slowly. Thus, it results from the performed numerical experiments that the adaptation period is followed by quasi-stationary change in the Black Sea stratification. The notion of quasistationarity made it possible to construct an analytical description of long-term evolution of density stratification in a rotating cylindrical basin being affected by the buoyancy flows through the lateral boundaries; it implied the prospect of application to the Black Sea $[5,6]$.

Based on the additional numerical experiments, the present paper represents a complete idea of formation and long-term evolution of haline stratification in the Black Sea basin.

Vertical motions in the Black Sea and their influence on formation of the main halocline are discussed in the first section; the time period of settling of the upper and lower Bosporus currents and the ratio of their discharges are described in the second section; quasi-equilibrium mode of the haline stratification evolution and the concept of a halocline as an internal boundary layer are discussed in the third section; using the resulted from the numerical experiments power law of the salt diffusion flow through the halocline upon the salinity difference in the layers above and below the pycnocline, constructed is the analytical model of long-term evolution of the haline stratification in the Black Sea, and its features are described in the fourth section; in conclusion, the obtained results are summarized and their importance is discussed.

\section{Vertical motions in the Black Sea and origine of the Black Sea halocline}

The balance estimates based on the assumption of the basin equilibrium (on average) state show that water upwelling is observed in the Black Sea center [7-9]. The numerical free run simulations which, on the whole, quite well reproduce the Black Sea pycnocline structure also confirm existence of water upwelling in the deep-sea part of the basin. Thus, the pycnocline in the Black Sea is of the same origin as that in the mid latitudes of the World Ocean. The origin of the Black Sea halocline was studied in details in a series of papers $[8,10,11]$. These studies took into account such geographical features of the Black Sea basin as its relatively small size and simple configuration of its boundaries. Certain symmetry of circulation and stratification was also taken into consideration: presence of the Rim Current (RC) encircling the sea along its boundary, and the dome-like structure of the density field with the halocline rising to the surface in the sea center and its lowering near the boundaries. Such features of the Black Sea basin permitted to represent the observed processes as a scheme and to consider the problem on formation of water circulation and stratification in a rotating cylindrical basin being affected by the salt and fresh water flows at its boundaries. Laboratory studies of formation of water stratification and circulation being influenced by the buoyancy fluxes at the lateral boundaries were performed in $[10,11]$. These experiments showed that inflow of fresh and salt water through the boundaries of a rotating cylindrical basin led to formation of a sharp pycnocline and a cyclonic circulation at the basin surface. Thus, in a simple axisymmetric 
configuration, reproduced are the basic large-scale features of circulation and stratification in the Black Sea basin.

Advancing of these studies in [12] promoted obtaining (within the framework of the linearized model) the analytical solution of the problem on the flows in a rotating cylindrical basin caused by the buoyancy flows at its boundaries. The analytical solution, having been compared to the results of laboratory modeling, demonstrated an amazing correspondence between theory and experiment.

A more complete study of fluid stratification and circulation in a rotating cylindrical basin affected by the buoyancy flows was carried out in [11] in which the results of laboratory studies and numerical calculations were also compared. It was shown that the nonlinear terms in the equations of motion are quite small, and the main nonlinear effects occurring during formation of the basin circulation and stratification are manifested in the equation of heat or salt diffusion that is typical of the oceanic thermocline theory. In the laboratory experiments, water density sharply changes vertically in course of transition from heating to cooling of a lateral boundary. Outside this rather a thin layer, the density vertical gradient is negligible. Thus, two layers of almost homogeneous liquid separated by a sharp pycnocline, are formed in the basin. Within its limits, the scale of the water density vertical changes is significantly smaller than the cylinder height; it permits to characterize the pycnocline as an internal boundary layer.

The numerical calculations represented in [11] show that in the basin, two circulation cells are formed above and below the pycnocline. In the basin upper part, water rotates counterclockwise, and in the lower part - clockwise. Analysis of distributions of the density and current velocity and in the radial section shows that two boundary layers are formed in the basin. One of them is located by the wall; the water density in it changes insignificantly, and the radial velocity module is reduced to zero. Another one is internal; large vertical gradients of the seawater density are associated with it.

Thus, the laboratory experiments and the numerical calculations show that the pycnocline formed being affected by the buoyancy flows at the basin lateral boundaries, posses the features of an internal boundary layer. Existence of this layer is maintained by two oppositely directed circulation cells in a vertical plane.

Considering motions in a rotating cylindrical basin as an analogue of the Black Sea circulation, one can assume that the Black Sea halocline, just as the oceanic thermocline, is a boundary layer. At that, an important role in formation of the Black Sea halocline is played, as in the ocean, by upwelling of deep-sea waters in the basin center.

\section{Water exchange through the Bosporus, characteristic time of its formation}

It was noted above that at present salinity of the Black Sea surface waters is about $18 \%$, and that of the waters inflowing with the lower Bosporus current about $36 \%$. Thus, if the basin current state is assumed to represent a balance of the salt inflow and outflow, the ratio of the water volume transport of the upper Bosporus current to that of the lower Bosporus one should equal two. At the same time, it is a priori not evident what is of primary importance: either the ratio of the volume transports of the upper and lower Bosporus currents or those of 
the currents in the strait adjust to salinity $18 \%$ in the Black Sea upper layer. To study this problem, a number of numerical experiments simulating exchange of the Black and Marmora seas' waters through the Bosporus, were carried out in [4]. A configuration including the interdisciplinary model Nucleus for European Modeling of the Ocean (NEMO) [13] was constructed for performing simulations. It implements the most common types of the state equations from which the UNESCO formula was chosen [14]. On the sea surface, a kinematic condition on the basis of which the level is calculated is prescribed. At that, the time-splitting scheme into fast (barotropic) and slow (baroclinic) modes is used [15]. Discretization of the equations' system was performed on the Arakawa's " $C$ " grid [16]. The TVD-scheme is used for the nonlinear summands in the transportdiffusion equations [17]. Vertical turbulent mixing in the model is calculated using the closure hypothesis $k-\varepsilon$ [18]. The regular geographic grid covering the basins of the Black, Azov and Marmora seas is preset in it; its horizontal step is about $20 \mathrm{~km}$. The model resolution for the Azov, Black and Marmora seas was sufficiently rough in order to have a possibility to carry out calculations for a long period. Topography of the Black Sea bottom was built using the digital array data in [19]. Vertical discretization was done on 34 non-regular $z$-horizons with the resolution increasing near the surface. The time step was 10 minutes.

The chosen grid step is unacceptably large for describing water exchange through the Bosporus Strait. In this connection, the artificial method of a "partially closed cells" was used to calculate the flows in the strait [13]. Due to this method, the grid cell size in the Bosporus was reduced to $2 \mathrm{~km}$. Five numerical experiments were performed in this configuration; they permitted to reveal influence of the initial conditions on water exchange through the Bosporus Strait. Uniform initial salinity $-8,12,16,18$ and $22 \%$ - prescribed as the initial conditions in the experiments. Temperature at the initial moment is everywhere uniform and amounts $6{ }^{\circ} \mathrm{C}$. The initial level surface in all the seas is set the same. In the Marmora Sea, the temperature and salinity initial values corresponded to its present state. For the basin boundaries in the mouths of 11 major rivers of the Black and Azov seas, the present climatic runoff and the temperature values with a seasonal cycle and also the zero salinity values were used. For the Marmora Sea, the open boundary with the preset temperature and salinity profiles and the free flow condition were applied. On the sea surface, the basin averaged difference between precipitation and evaporation was specified.

Analysis of time variability of the flow rates of the upper and lower Bosporus currents showed that in each of the experiments, water exchange through the Bosporus reached a steady-state regime after about the $20^{\text {th }}$ calculation year. The calculations also demonstrated that different initial salinity rather weakly affected the ratio of the flow rates of the upper and lower Bosporus currents in a steady state. When the Black Sea initial salinity is within the range 8-22\%o, it turns out to be close to two. Thus, one can conclude that salinity of the Black Sea upper layer (in its present state) is conditioned by the ratio of the flow rates through the Bosporus Strait.

In [20], dependence of the ratio of the flow rates of the upper and lower Bosporus currents upon the magnitude of the river fresh water inflow was also analyzed. The calculations showed that increase of the rivers' runoff was 
accompanied by growth of this ratio. Consequently, the ratio, close to two, between the flow rates of the upper and lower Bosporus currents is conditioned by the magnitude of the climatic rivers' runoff characteristic of the $20^{\text {th }}$ century.

\section{Notion of a quasistationary character of the stratification long-term evolution}

Five numerical simulations described in the previous section were proceeded for the period up to 70-100 years in order to assess the characteristics of circulation and haline stratification depending on the preset initial salinity. The calculation results showed that in each of the experiments, first of all a relatively rapid formation of vertical haline stratification occurred. Being affected by the rivers' runoff, significant desalination of the upper 40-meter layer takes place. In the deeper layers, gradual salinity increase due to the inflow of highly salt Marmora Sea waters is observed. Desalination of the surface seawater and its salination at the depths $>40 \mathrm{~m}$ leads to formation of a halocline in a layer $10-40 \mathrm{~m}$. It was noted in [21] that such location of the halocline was conditioned by the depth at which the inflow of highly saline Marmora Sea waters had got to the Black Sea.

In each of the calculations, the surface layer desalination lasts 70-80 years, whereupon its salinity starts to grow slowly. By this time below halocline, the salinity vertical gradient goes down almost to zero. Then, salinity, just as at the surface, slowly increases with time remaining almost constant over depth down to the sea bottom. Thus, the numerical experiments showed that, when calculations were performed with different initial conditions, the adaptation stage was first observed; it lasted approximately $70-80$ years. In course of this time period, a halocline is being formed near the sea surface. Then slow salination of the basin at all the depths takes place. Typical vertical profiles of the Black Sea average salinity are shown in Fig. 1.
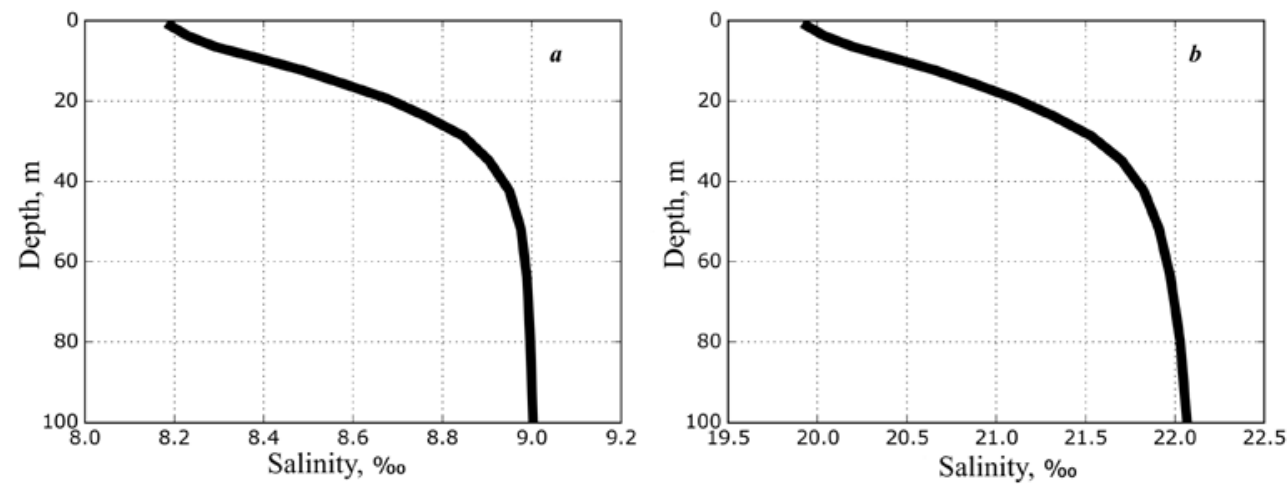

F i g. 1. Basin averaged salinity profile for the last year of calculation at initial salinity $8 \%-a$ and $22 \%-b$

Difference between the surface and bottom salinities increases with growth of the initial one. Salt water inflow is at the insignificant depth; as a result the halocline extends almost to the sea surface. Nevertheless, the above 
calculations are quite comparable with the results in [9]. This provides the grounds to claim that the reproduced halocline possesses the boundary layer features not only in the final stationary state, but also in course of a quasistationary evolution of the seawater salinity and density fields. Both the water exchange through the Bosporus and the river runoff form a large-scale water circulation in the Black Sea. Its character varies significantly depending on the basin-average salinity. At low salinity at the sea surface, the pronounced transport of the transformed river waters (inflow is in the northwestern part of the sea) along the western coast up to the mouth of the Bosporus is reproduced. In the rest of the basin, the circulation of water is rather chaotic, though its motion from the Kerch Strait mouth towards the Bosporus can be observed (Fig. 2,a). Increase of the basin averaged salinity in the surface layer is accompanied by prevailing of (the water mass) cyclonic motion of the water mass (Fig. 2, $b, c$ ).

On the whole, long-term calculations of the haline circulation in the Black Sea for different initial salinity show that the characteristic time of adaptation of the basin stratification to the changes in the external conditions constitutes $70-100$ years. After the equilibrium regime is achieved, slow quasi-stationary evolution of the basin fields takes place.

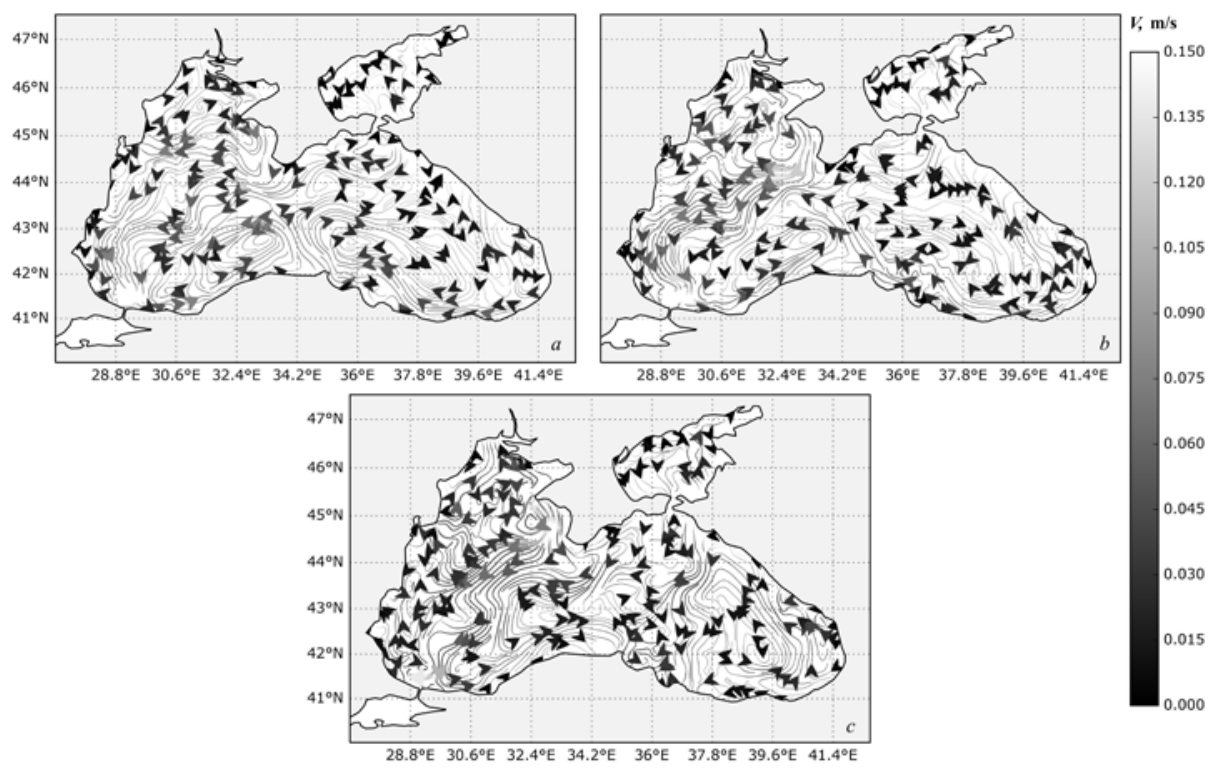

F i g. 2. Fields of the surface current velocities for the last year of simulations for initial salinity values $12 \%-a, 18 \%-b$ and $22 \%-c$

\section{Equations for describing slow evolution of the haline stratification}

Based on the results in $[4,20]$ and proceeding from the dimensional analysis, a simple parameterization of "density fluxes" through the pycnocline in a rotating cylindrical basin was proposed in [5]. Similar parameterization is also deduced for a rotating basin of an arbitrary configuration (see the appendix). Analysis of the results of the numerical experiments carried out in [6] showed that the average salinity gradient in a halocline was proportional to difference of salinities on PHYSICAL OCEANOGRAPHY VOL. 26 ISS. 6 (2019) 
the basin surface and bottom with the (index) power 1.27. It is close to the power $4 / 3$, which follows from the dimensional analysis for a rotating cylindrical basin. Increase of the salinity gradient in the halocline turns out to be not proportional to the salinity difference between the surface and bottom layers. This is related to the fact that increase of the salinity difference between the surface and bottom layers is accompanied by the halocline intensification.

Presence of a connection between the salinity diffusion flux through the halocline and the salinity difference between the surface and deep waters permits to construct the equation for salinity evolution in the layers above and below the halocline. At that, one should take into account the following: a boundary-layer character of the halocline, its small thickness and the fact that salinity above and below the halocline weakly varies vertically. Having integrated the equation of salt diffusion over the volumes above and below the halocline, we obtain the following two approximate equations:

$$
\begin{gathered}
V_{-} \frac{d S_{-}}{d t}=-Q_{b}^{-} S_{-}-\Gamma_{h}+Q_{b}^{+} S_{+}, \\
V_{+} \frac{d S_{+}}{d t}=Q_{b}^{+} S_{b}+\Gamma_{h}-Q_{b}^{+} S_{+},
\end{gathered}
$$

where $S_{+}, S_{-}$are the salinities in the layers below and above the halocline, respectively; $V_{+}$and $V_{-}$are the volumes of the near-surface and deep layers; $Q_{b}^{+}$and $Q_{b}^{-}$are the flow rates of the upper and lower Bosporus currents; $S_{b}$ is the Marmora Sea water salinity; $\Gamma_{h}$ is the integral diffusion salt flow through the halocline. Proportionality between the salt diffusion flow through the halocline and the difference between the lower and upper layers' salinities is revealed:

$$
\Gamma_{h}=-\left.\kappa \frac{d s}{d z}\right|_{h} A_{h} \approx-\kappa \frac{\Delta S_{h}}{H_{h}} A_{h},
$$

that makes the system of equations closed. Note that the found in [6] dependence also permits to determine the proportionality coefficient in formula (3):

$$
\Gamma_{h} \approx-0,532 \frac{\kappa A_{h}}{H_{h}}\left(S_{+}-S_{-}\right)^{1,27}
$$

In addition to the salinity diffusion flux, equation (2) takes into account its advective transport through the halocline associated with preservation of the lower layer volume and also compensating the inflow of the Marmora Sea waters.

Let us first analyze the final stationary state, which is achieved in the process of evolution of the Black Sea haline stratification. Equating the right-hand parts of equations (1) and (2) to zero, we obtain the following algebraic equations: 


$$
\begin{aligned}
-Q_{b}^{-} S_{-}-\Gamma_{h}+Q_{b}^{+} S_{+} & =0 \\
Q_{b}^{+} S_{b}+\Gamma_{h}-Q_{b}^{+} S_{+} & =0
\end{aligned}
$$

Summing up the left-hand parts of these equations, we obtain the ratio of the external salt balance

$$
Q_{b}^{+} S_{b}=Q_{b}^{-} S_{-}
$$

If the volume transport of the upper Bosporus current is assumed to be two times greater than that of the lower Bosporus one, and having preset the Marmora Sea salinity equal to $36 \%$, we find that $S_{-}=18 \%$. Combining equations (4) and (5), we can derive the following equation for the salinity difference between the upper and lower layers:

$$
S_{b}-2\left(S_{+}-S_{-}\right)-1,06 \frac{\kappa A_{h}}{H_{h} Q_{b}^{+}}\left(S_{+}-S_{-}\right)^{1,27}=0 .
$$

According to the results of the numerical experiments, the halocline depth is preset to be $25 \mathrm{~m}$ and its thickness $-30 \mathrm{~m}$, then for the present configuration of the Black Sea we find $V_{+}=525000 \mathrm{~km}^{3}, V_{-}=10000 \mathrm{~km}^{3}, A_{h}=390000 \mathrm{~km}^{2}$, $H_{h}=30 \mathrm{~m}$. Let us also preset the vertical turbulent diffusion coefficient as it was used in the numerical calculations: $\kappa=0.03 \mathrm{~cm}^{2} / \mathrm{s}$. Then, having solved equation (7), we find $S_{+}-S_{-}=4.27 \%$. This value of the salinity difference is close to that observed in the Black Sea.

Let us consider briefly the regularity of temporal evolution of the Black Sea haline stratification. First of all, note that the volume of the layer above the halocline is substantially smaller than that of the lower layer. Therefore, in the mode of slow evolution, the role of the nonstationary (summand) term in equation (1) is negligible and equation (4) can be used instead. Let us use the salinity difference instead of the upper layer salinity from equation (4) and transform equation (2) accordingly. As a result, we obtain the equation describing temporal evolution of the salinity difference through the halocline:

$$
\frac{d\left(S_{+}-S_{-}\right)}{d \tau}=\frac{S_{b}-2\left(S_{+}-S_{-}\right)}{2+1,27 \alpha\left(S_{+}-S_{-}\right)^{0,27}}
$$

where $\alpha=\frac{\gamma A_{h}}{H_{h} Q_{b}^{+}}$and $\tau=\frac{Q_{b}^{+} t}{V_{+}}$. In this equation, the right-hand side, at constant flow rates through the Bosporus (and, hence, river runoff and the precipitation/evaporation difference), is the positive and monotonically decreasing function of salinity difference. Therefore, salinity difference will monotonously increase in time from the initial value to the equilibrium one 
obtained above in full accordance with the resulted derived from the numerical experiments with different initial conditions. If the flow rates through the strait depend on time, equation (8) should be integrated numerically, that ultimately provides a possible to make the salinity profiles in Fig. 1 and 2, and the current velocity maps conform to a specific time. Note that for the present configuration of the Black Sea basin and the flow rates through the strait, the characteristic time of slow evolution of the haline stratification constitutes 1750 years.

\section{Conclusion}

Analysis of the performed numerical experiments yielded new notions on the conditions of formation and long-term evolution of the haline stratification in the Black Sea. First, it is shown that the characteristic time scale of the formation period for the upper and lower Bosporus currents is 20 years. Rather a short period of adaptation of the water exchange through the Bosporus to the external conditions means that on a climatic scale, it should be in a quasi-equilibrium state. Moreover, regardless of salinity of the Black Sea upper layers, the ratio of the water volumes transported by these currents is $\sim 2$. This ratio exactly conditions the fact that the surface salinity in a steady state tends to $18 \%$. Besides, the numerical experiments show that the ratio of intensities of the upper and lower currents through the Bosporus Strait can vary depending on the magnitude of a river runoff, precipitation and evaporation. Note also that the model of currents in the Bosporus Strait applied in calculations is rough enough. That is why the represented conclusions are of a qualitative character.

The numerical experiments have also demonstrated that a quasistationary evolution of the basin haline stratification takes place on the large time scales. The calculations made it possible to evaluate the characteristic time of its adaptation to a quasistationary state as $80-100$ years. In course of this period, within the vertical distribution of seawater salinity, a halocline is being formed. Having been compared to the results of the laboratory experiments, the calculations permit to characterize the developing halocline as an internal boundary layer existing at all the stages of evolution of the haline stratification in the Black Sea.

The idea of a quasistationary character of long-term evolution of the Black Sea haline stratification, and of the halocline as an internal boundary layer has provided the grounds for studying the relationship between the difference of salinities in the layers above and below the halocline, and the salt diffusion flow through it. The dimensional analysis is followed by the simple power law between these values with the exponent $4 / 3$. Processing the results of numerical experiments confirmed existence of a power dependence with the exponent 1.27 that is in good agreement with the theoretical forecast.

Revealing of functional dependence of the salt diffusion flow through the halocline with the difference of salinities in the layers above and below it, made it possible to propose a simple analytical model of climatic evolution of the Black Sea haline stratification. Based on the salt balance equations, the model forecasts monotonic tendency of the basin haline stratification to the equilibrium state close to that observed today. Along with general increase of the salt stock, the evolution process should be accompanied by increase of difference of salinity in the layers located above and below the halocline. Besides, since the pycnocline thickness is 
proportional to the salinity difference to the power of $1 / 3$, it will decrease with time. It is interesting to note that the results of processing the observations from $[1,2]$ show that both of these tendencies were observed during past 100 years. Thereupon, it seems advisable to consider the following issue: is the present state of the Black Sea basin in equilibrium.

However, it should be noted, that the results represented in this paper should be treated as a preliminary concept. The halocline formed in the numerical experiments, having been compared to that formed in the actual conditions, turns out to be too shallow. This is due to significant influence of wind mixing and heat exchange with the atmosphere upon the vertical structure of the sea upper layer fields. Wind mixing and seasonal variation of the heat flows on the sea surface result in formation of the upper mixed and the cold intermediate layers, which presumably, push off the described in this paper halocline deeper. The additional effect that is to be taken into consideration is related to subduction of cold waters from the Black Sea northwestern shelf [22] and from the upper parts of cyclonic gyres [23]. The wind effect, along with the upper layer mixing, leads to formation of the Rim Current and to the associated with it surface salinity change through its front. Due to this fact, salinity in the central and coastal parts of the sea is different; and when modeling the long-term evolution of the Black Sea stratification, one should necessarily take into account both the transfrontal salt transport by the mesoscale eddies [24, 26-28] and the seasonally varying Ekman transport [25-28].

Note that the regularities revealed in this article show that the vertical cells maintaining the halocline existence respond slowly to the changes in the external conditions. A sharp change in the external conditions should affect the structure a circulation vertical cell maintaining existence of a halocline in course of a period of several hundred years. Being applied to the problem of response of a thermal conveyor to the changes in climatic conditions, the results represented above mean that the heat transfer inertia in the temperate latitudes is to a great extent conditioned by the temperature drop between the surface and deep-sea layers of the ocean. Even significant variations of the conditions in the regions of deep water formation will change intensity of water upwelling at the lower boundary of the oceanic thermocline only after the temperature difference between the surface and deep-sea layers alters. The time of a thermohaline circulation cell transformation with water rising at the equator and lowering at high latitudes will depend on the rate at which the features of the deep-sea water masses change.

\section{Appendix}

If the Black Sea halocline is assumed to possess the features of a boundary layer, it is described by the following system of equations:

$$
\begin{array}{r}
-f_{v}=-\frac{d p}{d x}+A \Delta U, \\
f_{u}=-\frac{d p}{d y}+A \Delta V,
\end{array}
$$




$$
\begin{gathered}
\frac{d p}{d z}=g \rho \\
\frac{d U}{d x}+\frac{d V}{d y}+\frac{d W}{d z}=0 \\
U \frac{d \rho}{d x}+V \frac{d \rho}{d y}+W \frac{d \rho}{d z}=\kappa \frac{d^{2} \rho}{d z^{2}}
\end{gathered}
$$

where $U, V, W$ are the components of current velocity; $p$ is the pressure normalized to the average density; $\rho$ denotes here simga-t density also normalized to the average density; $g$ is the gravity acceleration; $f$ is the Coriolis parameter; $A$ is the horizontal turbulent viscosity; $\kappa$ is the vertical turbulent diffusivity. Equations $(1 \mathrm{~A})-(5 \mathrm{~A})$ should be solved in an infinite domain with $z$ varying from $-\infty$ to $\infty$, and horizontally - over the Black Sea basin area. Above and below the pycnocline, density tends to the constant values of $\rho_{-}$and $\rho_{+}$.

Cross-differentiating equations (1A) and (2A) and applying the horizontal divergence operation, we obtain two new equations:

$$
\begin{gathered}
-f_{\Omega}=-\Delta p, \\
f D=A \nabla \Omega,
\end{gathered}
$$

where $\Omega=\frac{d V}{d x}-\frac{d U}{d y} ; D=\frac{d U}{d x}+\frac{d V}{d y}$. In equation (6A) the geostrophic character of the main horizontal motions is taken into account. Now let us introduce the scale of the pycnocline $H$ and that of the density difference between the upper and lower layers $\delta \rho=\rho_{+}+\rho_{-}$. Then the pressure scale is equal to $g \delta \rho H$, the geostrophic velocity scale - to $\frac{g \delta \rho H}{f L^{2}}$, where $L$ is the basin characteristic size (for example, the square root of its area). The vorticity scale is equal to $\Omega=\frac{g \delta \rho H}{f L^{2}}$, and that of the horizontal divergence $-D=A \frac{g \delta \rho H}{f^{2} L^{4}}$. Finally, by virtue of (4A) and (5A), the vertical velocity scale equals $W=A \frac{g \delta \rho H^{2}}{f^{2} L^{4}}=\frac{\kappa}{H}$. The latter expression yields the pycnocline vertical scale:

$$
H=\left(\frac{\kappa f^{2} L^{4}}{g \delta \rho A}\right)^{\frac{1}{3}}
$$


Note that expression (8A) includes an unknown density difference $\delta \rho$. It remains undefined according to the concept of the pycnocline existence as a boundary layer at the stage of slow evolution of the basin stratification. Let us also calculate the scale of the diffusion "density flux" through the pycnocline:

$$
\Gamma=\kappa^{\frac{2}{3}}(g \delta \rho)^{\frac{4}{3}}\left(\frac{A}{f^{2} L^{4}}\right)^{\frac{1}{3}} .
$$

Thus, we find that the diffusion "density flux" through the pycnocline is proportional to the density difference below and above the pycnocline to the power of $4 / 3$ at the whole stage of slow evolution of the basin stratification.

\section{REFERENCES}

1. Altman, E.N., Gertman, I.F. and Golubeva, Z.A., 1988. [Multi-Year Tendencies of the Black Sea Salinity and Temperature in View of the River Runoff Change (Based on in situ Observations)]. In: SOI, 1988. SOI Proceedings. Leningrad: Gidrometeoizdat. Issue 189, pp. 39-53 (in Russian).

2. Polonsky, A.B., Shokurova, I.G. and Belokopytov, V.N., 2013. Decadal Variability of Temperature and Salinity in the Black Sea. Morskoy Gidrofizicheskiy Zhurnal, (6), pp. 27-41 (in Russian).

3. Ryan, W.B. and Pitman, W.C., 1999. Noah's Flood: The New Scientific Discoveries about the Event that Changed History. New York: Simon and Schuster, 319 p.

4. Senderov, M.V. and Mizyuk, A.I., 2017. Influence of Initial Conditions in the Problem of the Vertical Haline Structure Formation in the Black Sea Caused by Water Exchange Through the Bosphorus Strait and River Runoff. In: MHI, 2017. Ecological Safety of Coastal and Shelf Zones. Sevastopol: Marine Hydrophysical Institute of RAS. Vol. 2, pp. 82-89 (in Russian).

5. Korotaev, G.K., 2019. Formation of Salinity and Density Vertical Stratification of the Black Sea. Journal of Physics: Conference Series, [e-journal] 1359(1), 012003. doi:10.1088/17426596/1359/1/012003

6. Senderov, M.V., Mizyuk, A.I. and Korotaev, G.K., 2019. Study of the Formation of the Black Sea Haline Stratification from the Numerical Simulations. Journal of Physics: Conference Series, [e-journal] 1359(1), 012076. doi:10.1088/1742-6596/1359/1/012076

7. Vodyanitsky, V.A., 1948. [Basic Water Exchange and Background of the Black Sea Salinity Formation]. In: AS USSR, 1948. Proceedings of the Sevastopol Biology Station. Vol. 6, pp. 386-432 (in Russian).

8. Bulgakov, S.N. and Korotaev, G.K., 1989. [The Role of Haline Factors in Formation of the Black Sea Water Circulation]. In: AS USSR, 1989. Modeling of the Hydrophysical Processes and Fields in the Closed Basins and Seas. Moscow: Nauka, pp. 71-79 (in Russian).

9. Ivanov, L.I. and Samodurov, A.S., 2001. The Role of Lateral Fluxes in Ventilation of the Black Sea. Journal of Marine Systems, [e-journal] 31(1-3), pp. 159-174. doi:10.1016/S09247963(01)00051-3

10. Bulgakov, S.N., Korotaev, G.K. and Whitehead, J.A., 1996. The Role of Buoyancy Fluxes in the Formation of a Large-Scale Circulation and Stratification of Sea Water: 2. Laboratory Experiments. Izvestiya, Atmospheric and Oceanic Physics, [e-journal] 32(4), pp. 506-513.

11. Whitehead, J.A., Korotaev, G.K. and Bulgakov, S.N., 1998. Convective Circulation in Mesoscale Abyssal Basins. Geophysical \& Astrophysical Fluid Dynamics, [e-journal] 89(34), pp. 169-203. doi:10.1080/03091929808203685

12. Pedlosky, J., Whitehead, J.A. and Veitch, G., 1997. Thermally Driven Motions in a Rotating Stratified Fluid: Theory and Experiment. Journal of Fluid Mechanics, [e-journal] 339, pp. 391-411. doi:10.1017/S0022112097005168 
13. Madec, G., 2008. NEMO Ocean Engine. Note du Pôle de Modélisation. Technical Report. [e-book] France: Institut Pierre-Simon Laplace. No. 27. Available at: https://www.nemo-ocean.eu/doc/node1.html [Accessed: 7 May 2019].

14. Fofonoff, N.P. and Millard Jr., R.C., 1983. Algorithms for the Computation of Fundamental Properties of Seawater. Paris, France: UNESCO, 53 p. Available at: http://hdl.handle.net/11329/109 [Accessed: 07 May 2019].

15. Roullet, G. and Madec, G., 2000. Salt Conservation, Free Surface, and Varying Levels: A New Formulation for Ocean General Circulation Models. Journal of Geophysical $\begin{array}{lllll}\text { Research: Oceans, } \quad \text { [e-journal] 105(C10), pp. 23927-23942. } & \text { 2 }\end{array}$ https://doi.org/10.1029/2000JC900089

16. Mesinger, F. and Arakawa, A., 1976. Numerical Methods Used in Atmospheric Models. Vol. I. WMO-ICSU Joint Organizing Committee, 64 p. Available at: http://twister.ou.edu/CFD2003/Mesinger_ArakawaGARP.pdf [Accessed: 07 May 2019].

17. Zalesak, S.T., 1979. Fully Multidimensional Flux-Corrected Transport Algorithms for Fluids. Journal of Computational Physics, [e-journal] 31(3), pp. 335-362. https://doi.org/10.1016/00219991(79)90051-2

18. Rodi, W., 1987. Examples of Calculation Methods for Flow and Mixing in Stratified Fluids. Journal of Geophysical Research: Oceans, [e-journal] 92(C5), pp. 5305-5328. https://doi.org/10.1029/JC092iC05p05305

19. Avdeev, A.I., 2001. [Development of the Method for Studying the Black Sea Bottom Relief and its Influence on the Processes in the Land-Sea Interface Zone]. In: MHI, 2001. Ecological Safety of Coastal and Shelf Zones and Comprehensive Use of Shelf Resources. Sevastopol: MHI. Vol. 4, pp. 179-187 (in Russian).

20. Senderov, M.V., Mizyuk, A.I. and Korotaev, G.K., 2018. The Bosphorus Exchange Flow Impact on the River Runoff. Journal of Physics: Conference Series, [e-journal] 1128(1), 012149. doi:10.1088/1742-6596/1128/1/012149

21. Korotaev, G.K., 1997. Circulation in Semi-Enclosed Seas Induced by Buoyancy Flux through a Strait. In: E. Özsoy, A. Mikaelyan (eds.), 1997. Sensitivity to Change: Black Sea, Baltic Sea and North Sea. NATO ASI Series (Series 2: Environment), vol. 27. Dordrecht: Springer. pp. 395-401. https://doi.org/10.1007/978-94-011-5758-2_30

22. Kolesnikov, A.G., 1953. [On Calculation of the Water Temperature Annual Variation in the Southern Seas]. In: MHI, 1953. Trudy MGI AN USSR [Proceedings of Marine Hydrophysical Institute, Academy of Sciences of USSR]. Moscow: Publ. House of AS USSR. Vol. 3, pp. 106-127 (in Russian).

23. Ovchinnikov, I.M. and Popov, Yu.I., 1987. Cold Intermediate Layer Formation in the Black Sea. Okeanologiya, 27(5), pp. 739-746 (in Russian).

24. Zatsepin, A.G., Ginzburg, A.I., Kostianoy, A.G., Kremenetskiy, V.V., Krivosheya, V.G., Stanichny, S.V. and Poulain, P.-M, 2003. Observations of Black Sea Mesoscale Eddies and Associated Horizontal Mixing. Journal of Geophysical Research: Oceans, [e-journal] 108(C8), 3246. https://doi.org/10.1029/2002JC001390

25. Kubryakova, E.A. and Korotaev, G.K., 2013. Seasonal Variability of Circulation and Formation of Surface Water Salinity in the Black Sea. Morskoy Gidrofizicheskiy Zhurnal, (3), pp. 3-12 (in Russian).

26. Zalesny, V., Diansky, N., Fomin, V., Moshonkin, S.N. and Demyshev, S.G., 2012. Numerical Model of the Circulation of the Black Sea and the Sea of Azov. Russian Journal of Numerical Analysis and Mathematical Modelling, [e-journal] 27(1), pp.95-112. https://doi.org/10.1515/rnam-2012-0006

27. Zalesny, V.B., Gusev, A.V. and Fomin, V.V., 2016. Numerical Model of Nonhydrostatic Ocean Dynamics Based on Methods of Artificial Compressibility and Multicomponent Splitting. Oceanology, [e-journal] 56(6), pp. 876-887.

28. Gusev, A.V., Zalesny, V.B. and Fomin, V.V., 2017. Technique for Simulation of Black Sea Circulation with Increased Resolution in the Area of the IO RAS Polygon. Oceanology, [ejournal] 57(6), pp. 880-891. https://doi.org/10.1134/S0001437017060054 
About the authors:

Artem I. Mizyuk - Senior Researcher, Marine Hydrophysical Institute of RAS (2 Kapitanskaya St., Sevastopol, 299011, Russian Federation), Ph. D. (Phys.-Math.), ORCID ID: 0000-0003-4885354x, ResearcherID: C-6125-2016, artem.mizyuk@mhi-ras.ru

Maksim V. Senderov - Junior Researcher, Marine Hydrophysical Institute of RAS (2 Kapitanskaya St., Sevastopol, 299011, Russian Federation), ORCID ID: 0000-0002-1025-590X, ResearcherID: J-9658-2018, maxim.senderov@mhi-ras.ru

Gennady K. Korotaev - Scientific Supervisor of Marine Hydrophysical Institute of RAS (2 Kapitanskaya St., Sevastopol, 299011, Russian Federation), Corresponding Member of RAS, Dr. Sci. (Phys.-Math.), Professor, ResearcherID: K-3408-2017, gkorotaev@gmail.com

Contribution of the co-authors:

Artem I. Mizyuk - analysis and preparation of primary conclusions, discussions of the article materials, text updating

Maksim V. Senderov - numerical experiments, analysis and preparation of primary conclusions, construction of figures, qualitative and quantitative analysis of the results, discussions of the article materials, text updating

Gennady K. Korotaev - general scientific supervision of the investigation, formulation of the investigation aims and tasks, development and scientific substantiation of the concept of the vertical haline structure formation in the Black Sea, provision with financial support, preparation of the text initial version

All the authors have read and approved the final manuscript.

The authors declare that they have no conflict of interest. 